Editorial

\title{
Foreword: Proceedings of the 3rd International Electronic Conference on Sensors and Applications ${ }^{\dagger}$
}

\author{
Stefano Mariani ${ }^{1, *}$, Francesco Ciucci ${ }^{2, *}$, Dirk Lehmhus ${ }^{3, *}$, Thomas B. Messervey ${ }^{4, *}$, \\ Alberto Vallan ${ }^{5, *}$ and Stefan Bosse ${ }^{6, *}$ \\ 1 Dipartimento di Ingegneria Civile e Ambientale, Politecnico di Milano, Piazza L. da Vinci 32, \\ 20133 Milano, Italy \\ 2 Mechanical and Aerospace Engineering \& Chemical and Biomolecular Engineering, \\ The Hong Kong University of Science and Technology Clear Water Bay Kowloon, Hong Kong, China \\ 3 ISIS Sensorial Materials Scientific Centre, University of Bremen, 28359 Bremen, Germany \\ 4 Research to Market Solution s.r.l., Pavia, Italy \\ 5 Politecnico di Torino, Department of Electronics and Telecommunications, corso Duca degli Abruzzi, 24, \\ I-10129 Torino, Italy \\ 6 Department of Mathematics and Computer Science, University of Bremen, 28359 Bremen, Germany \\ * Correspondence: stefano.mariani@polimi.it (S.M.); francesco.ciucci@ust.hk (F.C.); \\ dirk.lehmhus@uni-bremen.de (D.L.); thomas.messervey@r2msolution.com (T.B.M.); \\ alberto.vallan@polito.it (A.V.); sbosse@uni-bremen.de (S.B.) \\ + Presented at the 3rd International Electronic Conference on Sensors and Applications, \\ 15-30 November 2016; Available online: https://sciforum.net/conference/ecsa-3.
}

Published: 31 May 2017

This issue of Proceedings gathers the papers presented at the 3rd International Electronic Conference on Sensors and Applications (ECSA-3), held online on 15-30 November 2016 through the sciforum.net platform developed by MDPI. The annual ECSA conference was initiated in 2014 on an online basis only, to allow the participation from all over the world with no concerns of travel and related expenditures. This type of conference looks particularly appropriate and useful because research concerned with sensors is rapidly growing, and a platform for rapid and direct exchanges about the latest research findings can provide a further burst in the development of novel ideas.

ECSA-3 collected contributions concerning five thematic areas where sensors are changing science (Biosensors, Chemical Sensors, Physical Sensors, Sensor Networks, Applications) and six specific sessions (MEMS and NEMS, Smart Systems and Structures, Fiber Optic Sensors, Factories of the Future, Sensing Technologies for Water Resource Management, Sensors for the Monitoring of the Low Voltage Distribution Network and Transition to the Smart Grid), see http://sciforum.net/conference/ecsa-3. In total 42 technical contributions and 2 keynote presentations were gathered, and all went through an independent peer-review process.

A companion special issue of Sensors, see http://www.mdpi.com/journal/sensors/special_issues/ 3rd_ecsa, will collect full-length versions of some selected papers.

The conference was made possible thanks to the kind sponsorship of Nanotechnology News Network, AutoHarvest Foundation, Sensors Online, SENSORNETS 2017, 360bio, Sensor100. We would like to also warmly thank Harry Fu for his extraordinary editorial work and support before, during and right after ECSA-3.

Sponsors:

- Nanotechnology News Network http://www.nanotechnology.org.il/index.php?ln=en\&action=about

- AutoHarvest Foundation http://www.autoharvest.org/about.html 
- Sensors Online http://www.sensorsmag.com/

- $\quad$ SENSORNETS 2017 http://sensornets.org/

- 360bio http://360.bio/

- Sensor100 http://www.sensor100.com/

(C) 2017 by the authors. Submitted for possible open access publication under the terms and conditions of the Creative Commons Attribution (CC BY) license (http://creativecommons.org/licenses/by/4.0/) 